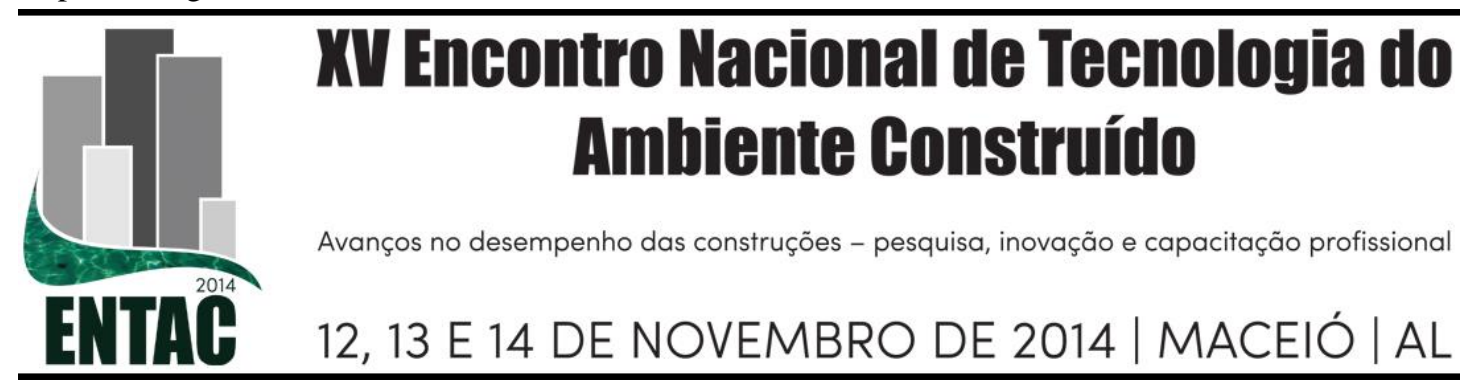

\title{
VIABILIDADE DA UTILIZAÇÃO DO CONCRETO DE ALTO DESEMPENHO EM SUBSTITUIÇÃO AO CONCRETO CONVENCIONAL
}

\author{
VALIN JR, Marcos de Oliveira (1); SILVA, Pedro Henrique de Almeira (2); \\ BRITO, Marcely Duany Correa (3); FLEURY, Luis Gustavo de Borba (4). \\ (1) Professor do Departamento da Área de Construção Civil do IFMT - Campus Cuiabá, \\ e-mail: marcos.valin@cba.ifmt.edu.br
}

(2, 3 e 4) Alunos do curso de Técnico em Edificações integrado com Ensino Médio e Bolsistas de Iniciação Cientifica CNPQ.

\begin{abstract}
RESUMO
O concreto é um material construtivo amplamente disseminado devido à sua versatilidade, durabilidade e resistência, podendo ser encontrado nas casas, em rodovias, pontes, nos edifícios mais altos do mundo e até em usinas e nucleares. A crescente preocupação com as questões de sustentabilidade tem motivado uma série de pesquisas voltadas para a reciclagem dos materiais, porém esta pesquisa pretende apresentar uma forma de minimizar a produção dos rejeitos, explorando as características de resistência e durabilidade dos Concretos de Alto Desempenho (CAD), onde se busca cada vez mais aprimorar a performance dos materiais, como alternativa sustentável para obras de edificação. Esta pesquisa trata-se de um projeto de iniciação cientifica do CNPQ na área de sustentabilidade. A metodologia adotada constituiu-se de revisão bibliográfica, entrevistas em concreteiras e construtoras, orçamentos, composições de custos e realização de ensaios para a verificação das propriedades do concreto convencional e o de alto desempenho (resistência à compressão axial, resistência à compressão diametral, absorção por imersão, absorção por capilaridade). Os resultados obtidos mostram que para a produção de $1 \mathrm{MPa}$ (Mega Pascal) de CAD utiliza-se menos cimento, um um dos grandes emissores de CO2, do que o necessário para produzir o mesmo $1 \mathrm{MPa}$ de concreto convencional. Entende-se que essa modalidade de concreto (CAD) apresenta uma minimização da produção dos rejeitos, maior resistência e durabilidade, o que implica em menores gastos com manutenção, melhor custo-benefício e menor produção de resíduos, otimizando os recursos naturais empregados na sua confecção. Além disso, o CAD consegue reduzir o peso próprio das estruturas, a taxa de armadura em peças sujeitas aos esforços de compressão e a área de formas, atendendo ao conceito de sustentabilidade da construção civil, priorizando o aumento significativo da área útil das edificações, atingindo alta performance. A principal contribuição da pesquisa é demonstrar a viabilidade desta tecnologia do concreto e que não deve ser limitada às obras de grande porte.
\end{abstract}

Palavras-chave: Concreto de Alto Desempenho, Viabilidade, Durabilidade, Sustentabilidade.

\begin{abstract}
Concrete is a constructive widespread because of its versatility, durability and resistance material, which can be found in homes, on highways, bridges, tallest buildings in the world and even in plants and nuclear. The growing concern with sustainability issues has motivated a lot of research for the recycling of materials, but this research aims to present a way to minimize the production of waste, exploring the characteristics of strength and durability of high performance concrete (CAD) where we seek increasingly enhance the performance of the materials as a sustainable alternative to building works

. This research is in a draft CNPQ scientific initiative in the area of sustainability. The methodology consisted of a literature review, interviews concrete producers and contractors, budgets, costs compositions and testing for the verification of the properties of conventional and high-performance concrete (compressive strength, resistance to diametrical compression, absorption dipping, wicking). The
\end{abstract}


results show that for the production of $1 \mathrm{MPa}$ (Mega Pascal) CAD less cement is used, one of the major producers of $\mathrm{CO} 2$, than that required to produce the same $1 \mathrm{MPa}$ conventional concrete. It is understood that this type of concrete (CAD) presents minimizing the production of waste, increased strength and durability, which implies lower maintenance costs, more cost-effective and produce less waste, optimizing natural resources used in its confection. In addition, the CAD can reduce the self-weight of the structures, the reinforcement ratio in parts subjected to compressive stress and the area of shapes, given the concept of sustainable construction, prioritizing the significant increase in the floor area of buildings reaching high performance. The main contribution of this research is to demonstrate the feasibility of this concrete technology and should not be limited to large works

Keywords: High Performance Concrete, Feasibility, Durability, Sustainability.

\section{INTRODUÇÃO}

O concreto é um material amplamente disseminado devido à sua versatilidade, durabilidade e resistência, podendo ser encontrado nas casas, em rodovias, pontes, nos edifícios mais altos do mundo, em usinas hidrelétricas e nucleares, em obras de saneamento e até em plataformas de extração petrolífera móveis e o Concreto de Alto Desempenho (CAD) é uma tecnologia com enormes potencialidades ainda a serem exploradas pelo mercado construtivo, sendo que atualmente são utilizadas somente para situações especiais como, por exemplo, em estruturas com cargas ou tensões de compressão elevadas, obras emergenciais ou de recuperação e estruturas submetidas a ambientes agressivos ou que necessitem de alta durabilidade.

Para ser considerado $\mathrm{CAD}$ é necessário apresentar uma resistência à compressão maior que $50 \mathrm{MPa}$, porém o American Concrete Institute - ACI (1991) ressalta outras propriedades especiais de desempenho, como a facilidade de lançamento e compactação do concreto sem que ele segregue; a baixa permeabilidade; a estabilidade volumétrica; e a durabilidade.

Para Aiticin (2000), um concreto de alto desempenho é essencialmente um concreto tendo uma relação água/ aglomerante baixa, cerca de 0,40 , esse é o valor sugerido como fronteira entre concretos usuais e concreto de alto desempenho. Quando a relação água/ aglomerante se afasta desse valor as características como resistência à compressão e retração desses concretos se tornam bem diferentes.

O CAD deve ser aliado com boas práticas construtivas como uma boa cura, confecção correta das formas e controle tecnológico, tornando-se durável e racional, no sentido de aproveitar ao máximo os recursos naturais empregados na sua produção, tornando-o uma alternativa sustentável que ofereça vantagens tecnológicas e econômicas em relação aos demais.

Liborio (2002) complementa que é um material, cientificamente produzido, que atende as expectativas do cliente do ponto de vista estrutural, da estética, de durabilidade frente ao meio ambiente atual e futuro, para fins pré-determinados. Deve ser econômico (custo/benefício) e propiciar vantagens frente a alternativas tecnológicas.

A sustentabilidade tem sido uma bandeira empunhada por profissionais de todas as áreas tecnológicas e científicas. A produção anual de cimento é responsável por 7,9\% de toda a emissão de CO2 no mundo inteiro (RESCHKE, et al., 2005 apud LIMA, 2008), fato que evidencia a necessidade da racionalização do uso deste material.

Para Almeida (2005), o CAD é uma evolução tecnológica dos concretos tradicionais, em que foram pesquisados novos produtos químicos e adições minerais tornando $o$ concreto mais resistente da ordem de três a cinco vezes superiores aos concretos convencionais. O Concreto de Alto Desempenho quando usado em peças estruturais, 
reduz áreas e volumes, proporcionando maior liberdade arquitetônica maior velocidade de construção; são aplicados também em pontes e obras de arte especiais recuperação de estruturas; aplicação em peças estruturais pré-fabricadas tem como vantagem a reutilização de formas mais rápida.

O Civil Engineering Research - CER descreve as propriedades necessárias em um CAD, como: facilidade de lançamento e compactação e altas resistências em pequenas idades. A definição consiste também, na apresentação de algumas diferenças entre o CAD e o concreto convencional: Maior resistência mecânica a longas idades e resistência à abrasão ou carga de impacto; Menor permeabilidade; Melhor estabilidade de volume e de forma; Maior durabilidade a ataque químico, exposição a ciclos de gelo e degelo e altas temperaturas;

Outra característica importante observada na confecção do CAD é o estudo dos agregados. Isso porque estes podem ser o elo fraco da mistura, quando o concreto atingir resistências elevadas (HELENE e TUTIKIAN, 2011).

Sobre este assunto, concorda SIMPLÍCIO (2013) ao dizer que os agregados são os componentes que irão limitar a resistência à compressão do concreto.

No caso do $C A D$, é preferível utilizar agregados graúdos de pequena dimensão (ABCP, 1999), porque quanto maior for a resistência à compressão pretendida, menor deve ser o tamanho do agregado graúdo (AITCIN, 2000). E quanto maior for a dimensão dos grãos dos agregados, maior será a zona de transição (MEHTA \& MONTEIRO 2008).

Posto a importância tanto para o desenvolvimento de estruturas de concreto duráveis, bem como para a otimização dos recursos naturais, este trabalho tem por objetivo apresentar resultados experimentais que comprovem a viabilidade da utilização do CAD em substituição ao concreto convencional em obras de edificações e também de apresentar a sua importância quando tratamos de sustentabilidade na construção civil.

\section{MATERIAIS E MÉTODOS}

A metodologia adotada consistiu em três etapas, sendo a primeira com a realização de um levantamento bibliográfico sobre o tema.

$\mathrm{Na}$ sequência foram realizadas entrevistas em concreteiras e construtoras de CuiabáMT, visando entender o mercado local e o conhecimento sobre essa tecnologia por aqueles que estão no dia a dia das obras e após realizada a tabulação das informações em planilhas e gráficos.

Por fim, na terceira etapa, realizou-se um estudo experimental, baseado na moldagem de corpos-de-prova de concreto variando as dosagens, conforme apresentado na tabela 1 , sendo 21 corpos-de-prova para cada condição e submetidos à cura úmida.

Tabela 1 - Identificação dos tipos e características dos traços experimentais

\begin{tabular}{|c|c|c|c|c|c|c|c|}
\hline Tipo & $1: \mathrm{M}$ & $\begin{array}{c}\text { Teor de } \\
\text { Argamassa }\end{array}$ & $\begin{array}{c}\text { Traço } \\
\text { (c:a:p:a/c) }\end{array}$ & a/c & $\begin{array}{c}\text { Brita } \\
\text { B2/ B1 }\end{array}$ & Aditivo & $\begin{array}{c}\text { Consumo de } \\
\text { cimento } \mathrm{m}^{3}\end{array}$ \\
\hline A & 5 & $47 \%$ & $1: 1,82: 3,18$ & 0,53 & $70 \% / 30 \%$ & $0 \%$ & $369,85 \mathrm{Kg}$ \\
\hline B & 3,5 & $47 \%$ & $1: 1,12: 2,38$ & 0,41 & $70 \% / 30 \%$ & $0 \%$ & $492,41 \mathrm{Kg}$ \\
\hline C & 3,5 & $47 \%$ & $1: 1,12: 2,38$ & 0,38 & $70 \% / 30 \%$ & $0,5 \%$ & $499,79 \mathrm{Kg}$ \\
\hline D & 3,5 & $53 \%$ & $1: 1,39: 2,10$ & 0,40 & $100 \% / 0 \%$ & $0,5 \%$ & $491,64 \mathrm{Kg}$ \\
\hline
\end{tabular}

Os concretos A, B, C e D foram dosados com base no método Helene e Terzian (1987).

Para o estudo foram utilizados corpos-de-prova cilíndricos de concreto com $10 \mathrm{~cm}$ de 
diâmetro e $20 \mathrm{~cm}$ de altura, dosados com os seguintes materiais: Cimento Portland CP II Z 32; Aditivo superplastificante; Agregados graúdos da região de Cuiabá: A massa unitária e a massa específica são respectivamente $1,50 \mathrm{~g} / \mathrm{cm} 3$ e 2,77 g/cm3; Agregado miúdo da região de Cuiabá: A massa unitária e massa específica são respectivamente: $1,73 \mathrm{~g} / \mathrm{cm} 3$ e 2,64 g/cm3; Água obtida diretamente da rede de abastecimento local.

Após o período de cura úmida, foram realizados os seguintes ensaios: resistência à compressão axial (NBR 5739/94), resistência à tração por compressão diametral (NBR 7222/94), absorção de água por imersão e índice de vazios (NBR 9778/87) e absorção por capilaridade (NBR 9779/95).

\section{RESULTADOS E DISCUSSÕES}

\subsection{Desempenho quanto a Resistência}

A resistência não é a única característica importante do concreto de alto desempenho, mas é uma das que definem o CAD. Para que um concreto seja considerado de alto desempenho sua resistência deve ser de no mínimo $50 \mathrm{MPa}$. Na figura 1 são apresentadas as resistências à compressão axial obtida aos 28 dias para os quatro traços apresentados na tabela 1. Na figura 2 são apresentadas as resistências à compressão diametral.

Analisando as figuras podemos perceber um aumento de $14,06 \%$ na resistência axial do concreto A para o B e o maior aumento da resistência diametral, de $26,92 \%$. Na produção do concreto $\mathrm{B}$ foram utilizados o mesmo percentual de empacotamento entre os agregados graúdos do concreto A, assim como o mesmo teor de argamassa, já o traço foi alterado, pois a proporção entre o cimento e os agregados foi diminuído de 5 para 3,5 e a relação água cimento obtida durante a mistura do concreto caiu de 0,52 para 0,41. Essa diminuição do a/c e a alteração do traço levaram ao aumento nas resistências axiais e diametrais.

Figura 1 - Resistência à compressão axial aos 28 dias.

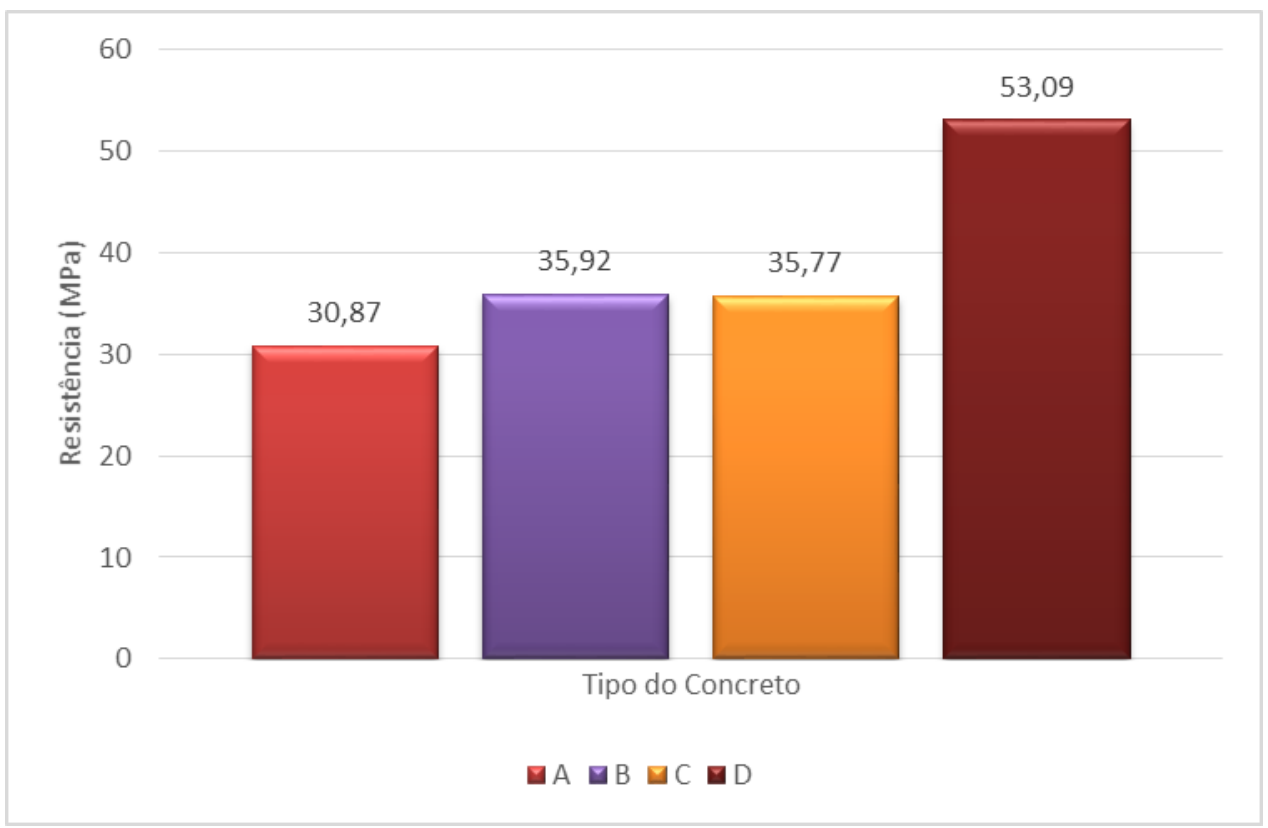


Figura 2 - Resistência à tração por compressão axial aos 28 dias.

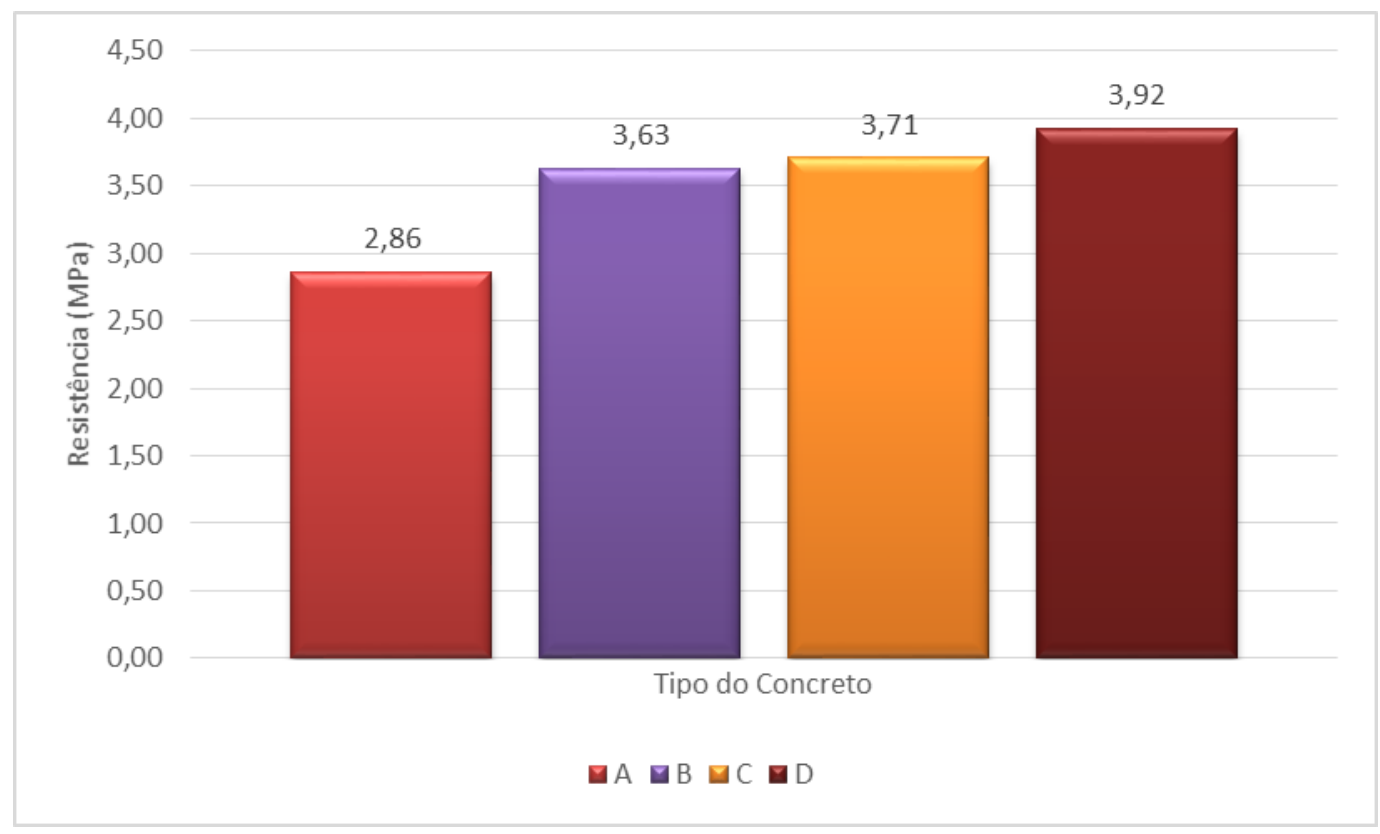

Entre os concretos $\mathrm{B}$ e $\mathrm{C}$ as resistências tanto axial quanto diametral os mantiveram-se próximas. $\mathrm{O}$ concreto $\mathrm{C}$ foi dosado com o mesmo traço do concreto $\mathrm{B}$, porém, desta vez fez-se uso de aditivo superplastificante reduzindo o a/c de 0,41 para 0,38 . A diminuição de 0,03 no valor do traço unitário da água não apresentou impacto na resistência, mas demonstrou grande influência na absorção como será explicado adiante.

Já entre os concretos $\mathrm{C}$ e D houve um grande aumento na resistência a compressão axial de $48,42 \%$, e $26,92 \%$ na resistência a compressão diametral. Na produção do concreto $\mathrm{D}$ foi utilizado o agregado graúdo com menor dimensão, o que levou à alteração no teor de argamassa, de $47 \%$ para $53 \%$, alterando então o traço como pode ser visto na tabela 1 , e a relação água/cimento obtida durante a mistura foi 0,40 mantendo-se no limite para o CAD. A partir desses dados podemos concluir que a substituição da brita de maior dimensão por uma menor resultou em um aumento significativo da resistência a compressão como citado anteriormente.

Do concreto A para o concreto D a resistência axial aumentou $72 \%$ e a diametral $37 \%$, esse aumento da compressão axial foi ocasionado por vários fatores como o aumento do consumo de cimento por causa da diminuição do total de agregados em relação ao cimento, a troca da brita 2 empacotada utilizada nos concretos A, B e C pela brita $1 \mathrm{o}$ que resultou no aumento do teor de argamassa de $47 \%$ para $53 \%$ e o uso do aditivo superplastificante.

\subsection{Desempenho quanto a Durabilidade}

A durabilidade no CAD tem um papel tão importante quanto a sua resistência, pois é com base nesse conceito que se constrói a ideia de sustentabilidade. A figura 3 apresentada os valores da absorção por capilaridade aos 28 dias dos 4 tipos de concreto produzidos, e na figura 4 são apresentados os valores dos ensaios de absorção por imersão. 
$\mathrm{Na}$ análise de dados do ensaio de Absorção por Capilaridade na idade de 28 dias, observou-se que o Concreto A apresentou absorção por capilaridade de 1,94\%, enquanto o Concreto B apresentou absorção por capilaridade de 0,98\%. Essa diminuição de $50,51 \%$ da absorção em relação ao Concreto $\mathrm{A}$ foi resultado da diminuição da quantidade de agregados.

O Concreto $\mathrm{C}$ apresentou absorção por capilaridade de $0,47 \%$ com a idade de 28 dias. A diminuição dos valores de absorção do Concreto $\mathrm{C}$ em relação ao Concreto $\mathrm{B}$ foi de $47,96 \%$ devido à utilização do aditivo superplastificante. Em relação ao Concreto $\mathrm{A}$, a redução foi de $75,25 \%$ como resultado da diminuição da quantidade de agregados e a utilização do aditivo plastificante.

Figura 3 - Absorção por capilaridade aos 28 dias.

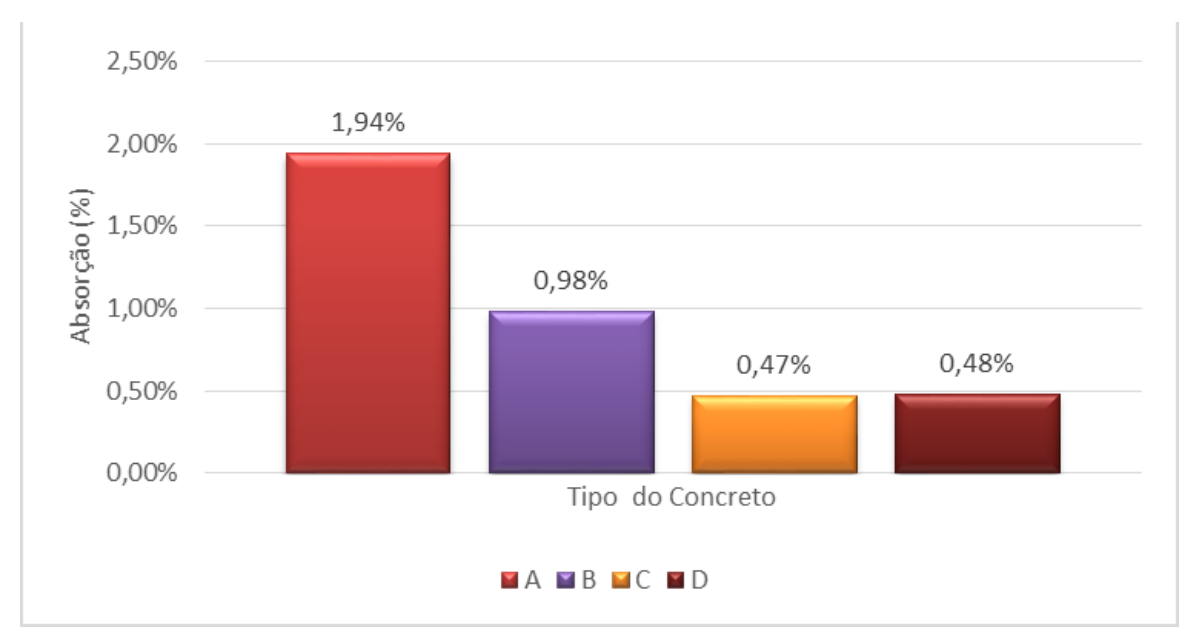

Figura 4 - Absorção por imersão aos 28 dias.

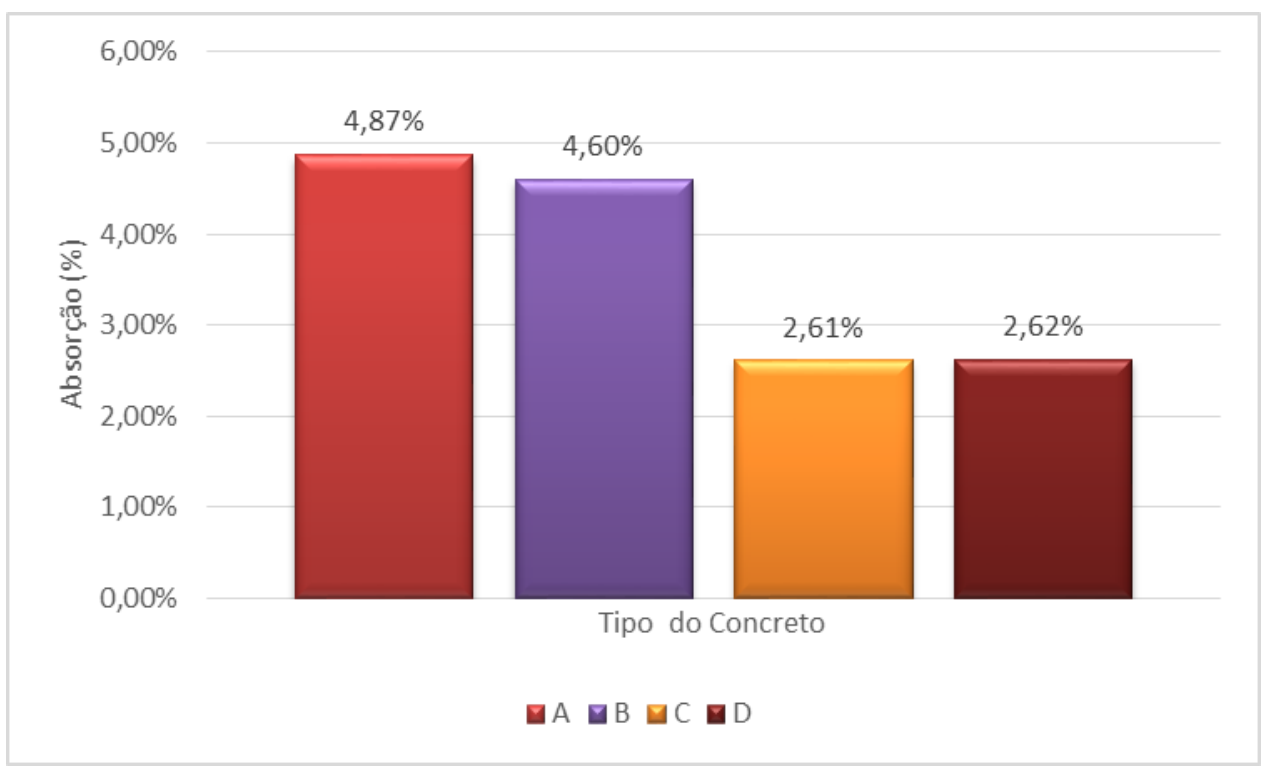

Já o Concreto $\mathrm{D}$ apresentou absorção por capilaridade de $0,48 \%$. Em relação ao Concreto $\mathrm{C}$, verificou-se uma estabilização no percentual de absorção, observando-se que o aumento no teor de argamassa e a utilização apenas de brita $n^{0} 1$ não influenciaram nos valores de absorção obtidos. 
Diante dessas observações, pode-se concluir que os valores obtidos a partir do Concreto $\mathrm{D}$ e C são aproximadamente 4 vezes menores que os obtidos a partir do Concreto A, fazendo com que os procedimentos e materiais usados nos concretos $\mathrm{C}$ e $\mathrm{D}$ sejam mais eficazes na diminuição absorção por capilaridade que os usados no Concreto A.

Já no ensaio de Absorção por imersão, o único ponto que divergiu da capilaridade, foi em relação ao concreto $\mathrm{B}$, que apresentou resultado similar ao $\mathrm{A}$, sendo que o $\mathrm{C}$ e $\mathrm{D}$ também foram mais eficazes nesta situação.

\subsection{Desempenho quanto a Custo}

Esta análise tem por objetivo mostrar o custo total dos materiais utilizados para a dosagem de diferentes traços, com e sem aditivo, mostrando assim um melhor custo/beneficio na utilização do CAD em relação ao concreto convencional tendo por base a resistência e durabilidade.

Para realização desse cálculo, foram considerados valores reais médios dos materiais na cidade de Cuiabá - MT, no ano de 2013, todos já convertidos para valores em massa $(\mathrm{Kg})$, conforme apresentados na Tabela 2.

Quando analisamos o custo dos materiais por $\mathrm{m}^{3}$ de concreto, conforme figura 5, é possível observar um menor custo para o Concreto A, tendo uma diferença de $\mathrm{R} \$ 48,20$ por $\mathrm{m}^{3}$ em relação ao segundo mais barato, o tipo D, de Alto Desempenho.

Todavia, quando calculamos o custo por Mpa (resistência), cujo cálculo é obtido pela razão entre o custo dos materiais por $\mathrm{m}^{3}$ pela resistência do concreto aos 28 dias, nota-se que o Concreto D (CAD) obtém-se um custo menor, conforme apresentado na figura 6 .

Tabela 2 - Valores médios dos materiais do concreto em Cuiabá - MT / 2013

\begin{tabular}{|l|lc|}
\hline \multicolumn{1}{|c|}{ Material } & \multicolumn{2}{c|}{ Preço por Kg } \\
\hline Cimento Portland CP II Z 32 & R\$ & 0,44 \\
\hline Areia & R\$ & 0,03 \\
\hline Brita & R $\$$ & 0,04 \\
\hline Aditivo Superplastificante & R $\$$ & 2,27 \\
\hline
\end{tabular}

Comparando, o de menor custo por Mpa (Concreto D) com o segundo mais barato (Concreto A), temos uma diferença considerável, $\mathrm{R} \$ 2,19$ por Mpa, isto é, o Concreto $\mathrm{D}$ se torna $42 \%$ mais barato. Calculando a diferença do custo por Mpa entre o Concreto D e o Concreto $\mathrm{C}$, temos $\mathrm{R} \$ 2,72$ de diferença que corresponde a um valor 52\% mais caro que o do concreto $\mathrm{D}$. 
Figura 5 - Custo dos materiais para produção de $1 \mathrm{~m}^{3}$ em cada tipo de concreto

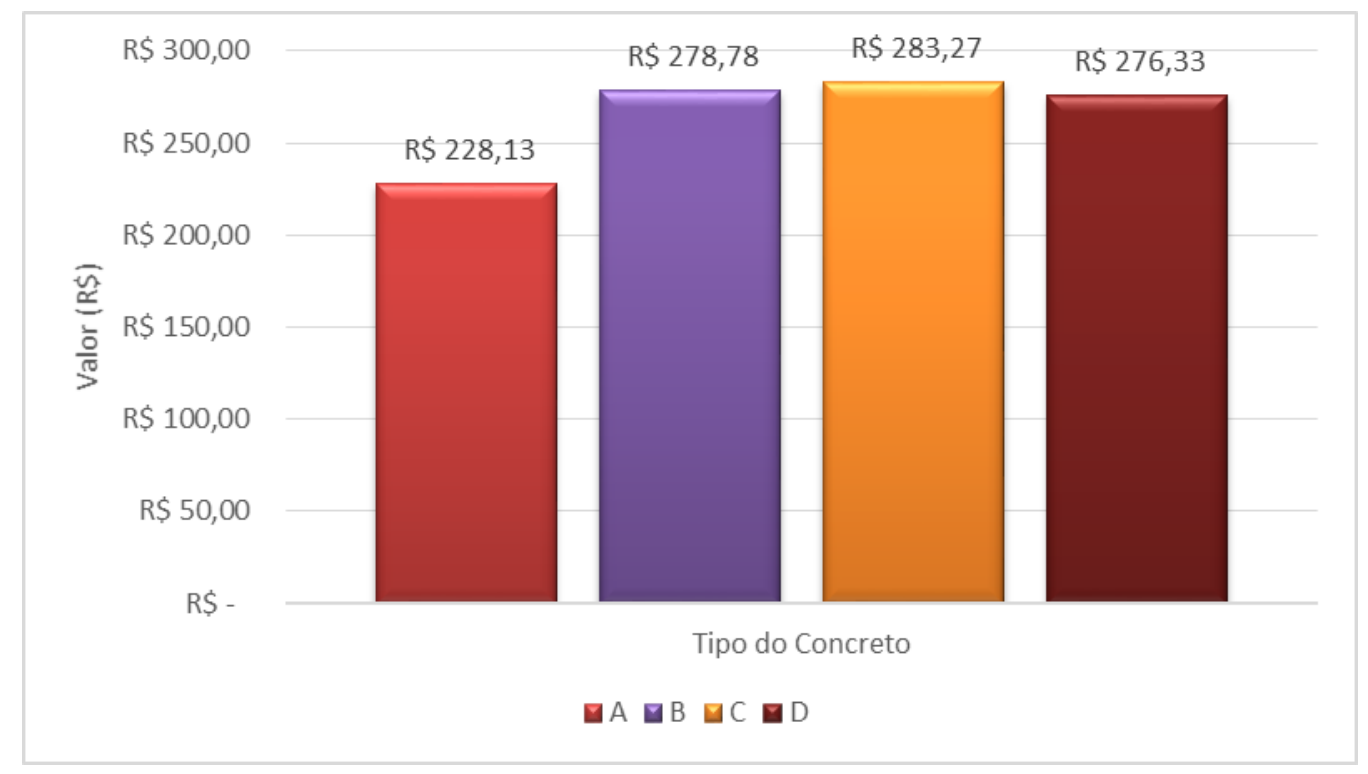

Figura 6 - Custo por MPa em cada tipo de concreto

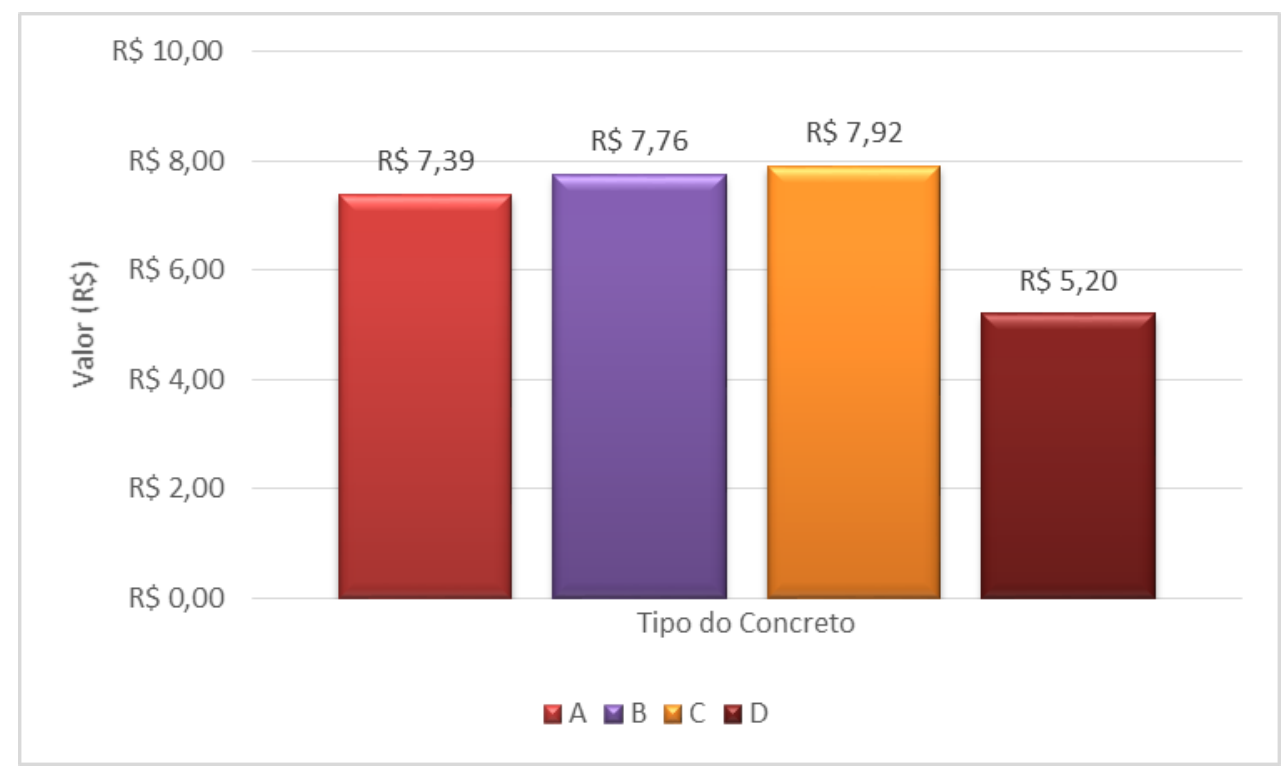

\subsection{Entrevista e Pesquisa de Mercado}

As entrevistas com os representantes das empresas que se voluntariaram a responder um questionário com perguntas relacionadas aos conhecimentos sobre Concreto de Alto Desempenho, obtiveram $71 \%$ de empresas que atuam a mais de 15 anos no mercado. Todas as empresas pesquisadas trabalham com obras de $1000 \mathrm{~m}^{2}$ ou mais.

Todas as obras pesquisadas utilizam concreto usinado, e 87,5\% dos entrevistados disseram que foi adotado um método de dosagem nas obras, porém não souberam especificar qual método.

Sobre a existência de um processo de cura na obra, que faz parte do controle tecnológico para a obtenção de um concreto de boa qualidade, $87 \%$ das empresas 
responderam que há sim um processo de cura e $13 \%$ afirmaram não utilizar nenhum processo de cura na obra em questão.

Quanto ao aparecimento de manifestações patológicas em obras já finalizadas, $50 \%$ afirmaram que não houve aparecimento de patologias, 37\% afirmaram que houve patologias como trincas e fissuras de retração e $13 \%$ não responderam, ou não souberam responder.

A figura 7 apresenta os resultados quanto aos conhecimentos sobre o Concreto de Alto Desempenho: $87 \%$ dos entrevistados afirmaram conhecer o CAD, porém $25 \%$ dos que afirmaram conhecer o CAD não souberam definir o conceito de Concreto de Alto Desempenho corretamente.

Figura 7 - "Você conhece o concreto de alto desempenho?"

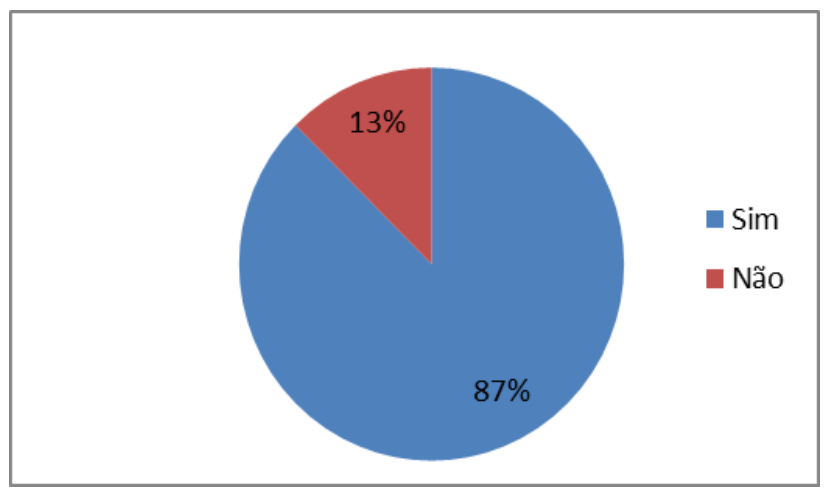

Nas entrevistas as empresas foram questionadas quanto à utilização do CAD, e $88 \%$ afirmaram nunca ter utilizado e $12 \%$ já utilizaram, mas sem frequência (figura 8 ).

Diante da pequena adesão do Concreto de Alto Desempenho observada nas pesquisas, os entrevistados foram questionados sobre o motivo que dificultaria o uso do CAD, conforme figura 9 , e $50 \%$ responderam que a maior dificuldade se encontrava no preço, $25 \%$ disseram que o problema está na falta de conhecimento sobre o CAD, $12 \%$ acreditam que o controle de qualidade é muito exaustivo. Em "outras respostas" que corresponderam a $13 \%$ do total de entrevistados, encontram-se respostas como a "falta de confiabilidade nas concreteiras e cimenteiras".

Figura 8 - Utilização do CAD em obras das empresas entrevistadas

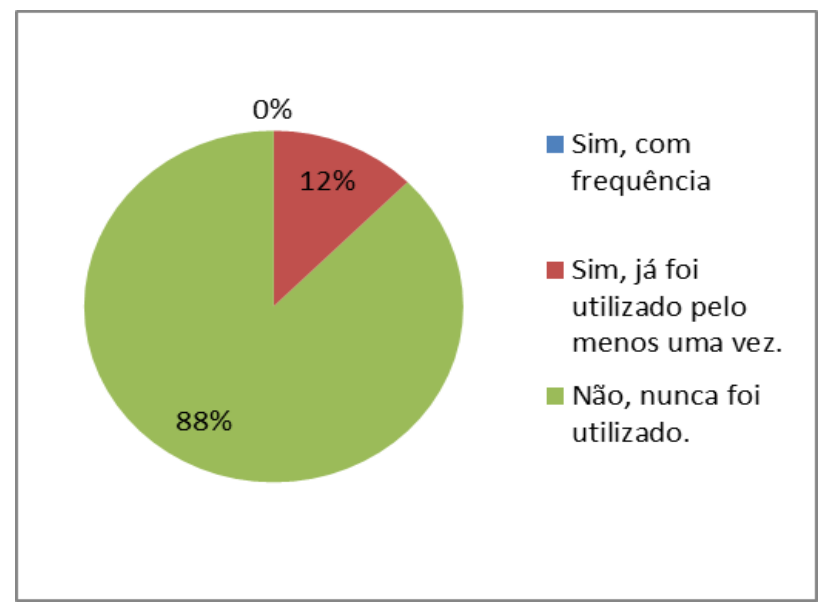




\section{Figura 9 - Dificuldades apresentadas na aplicação do CAD.}

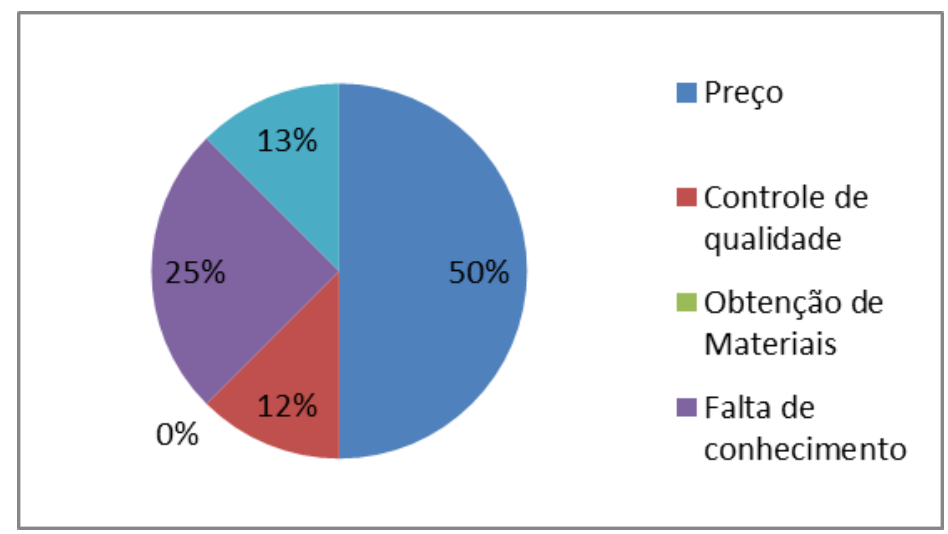

\section{CONCLUSÕES}

Pensando em sustentabilidade e viabilidade entende-se que o CAD é a melhor opção para a produção de concreto em obras de edificação devido sua alta resistência e durabilidade.

Com embasamento nos experimentos científicos podemos comprovar a viabilidade do CAD em relação aos concretos convencionais. Quando analisamos o custo de produção nota-se que entre o Concreto B (convencional sem aditivo plastificante) e o Concreto C (Com aditivo plastificante) houve uma pequena variação entre eles no custo dos materiais e na resistência. Porém, ao lançarmos mão de pesquisas e práticas que melhoram a performance dos concretos, encontramos um traço unitário ótimo, que resultou em uma melhor combinação e utilização dos materiais para a confecção de um Concreto de Alto Desempenho (Concreto D), que obteve aos 28 dias uma resistência superior aos concretos anteriores, um menor teor de absorção por capilaridade e imersão e uma vantagem na relação custo/benefício.

Constata-se que nem sempre o concreto mais caro é o mais durável ou o mais resistente, o Concreto de Alto Desempenho em comparação aos concretos comuns acaba adquirindo um custo maior na sua confecção, entretanto, quando se leva em consideração a durabilidade e a resistência, seu custo demonstrou-se consideravelmente menor.

$\mathrm{O}$ uso do $\mathrm{CAD}$ na construção civil não deve ser limitado às obras de grande porte. É possível produzir um concreto resistente, durável e barato com o aprimoramento de técnicas de dosagem e controle tecnológico.

Para trabalhos futuros recomenda-se realizar a quantificação do quanto o CAD permite o redimensionamento de pilares, onde a compressão é o elemento mais solicitado, e por consequência quantificar também a diminuição na área de fôrmas, o volume de concreto, o peso próprio e as taxas de armadura, que levam a um menor consumo de recursos naturais, ou seja, a sustentabilidade além do concreto propriamente dito, mas em todos os elementos relacionados.

\section{AGRADECIMENTOS}

Estamos gratos aos Técnicos e Estagiários do Laboratório de Materiais do IFMT Campus Cuiabá pelo apoio na realização dos ensaios. 
Agradecemos também aos Engenheiros Civis, Tecnólogos em Controle de Obras, Arquitetos, Técnicos em Edificações e Empresários que disponibilizaram alguns preciosos minutos para realização das entrevistas e preenchimentos dos questionários.

Esta pesquisa, desenvolvida no Departamento de Área de Construção Civil (DACC) do Instituto Federal de Educação, Ciência e Tecnologia de Mato Grosso (IFMT) - Campus Cuiabá, faz parte do Programa Institucional de Bolsas de Iniciação Científica no Ensino Médio - PIBIC EM CNPQ / IFMT, aplicada na área de Sustentabilidade, pelo qual dedicamos um agradecimento especial.

\section{REFERÊNCIAS BIBLIOGRÁFICAS}

AÏTCIN, P. C. Concreto de alto desempenho - Tradução de Geraldo G. Serra, São Paulo: PINI, 2000. 667p.

AMERICAN CONCRETE INSTITUTE (1991). Committee 363R. State-of-the-art report on high-strength concrete. ACI Manual of concrete practice, Detroit, part 1. 49p

ALMEIDA, Ivan Ramalho de. Concretos de Alto Desempenho. In: ISAIA, Geraldo Cechella. Concreto: Ensino, Pesquisa e realizações. São Paulo: Ibracon, 2005. V2, Cap. 38, p. 1159-1193.

ABCP - Associação Brasileira de Cimento Portland, Concreto de Alto Desempenho. Segundo CD-ROM, 1CD, versão I, 1999.

HELENE, Paulo R. L.; TUTIKIAN, Bernardo F. Dosagem dos Concretos de Cimento Portland. São Paulo: IBRACON, 2011. Cap. 12.

LIBORIO, J. B. L. Avanços tecnológicos dos concretos estruturais nos últimos 30 anos. IBRACON 30 ANOS. CD ROM. São Paulo, 2002.

LIMA, S. M. DE. Concreto de alto desempenho aplicado a sistemas de processamento e armazenagem de alimentos em baixas temperaturas. Tese (Doutorado). Escola de Engenharia de São Carlos, Universidade de São Paulo, São Carlos, 2008.

METHA, P. K., MONTEIRO, P. J. M.. Concreto: Microestrutura, Propriedades e Materiais. São Paulo, IBRACON, 2008.

SIMPLÍCIO, M. A. de S. Concreto de alto desempenho, vantagens e aplicações. Disponível em: http://www.altodesempenho.faithweb.com. Acesso em 11 nov. 2013. 